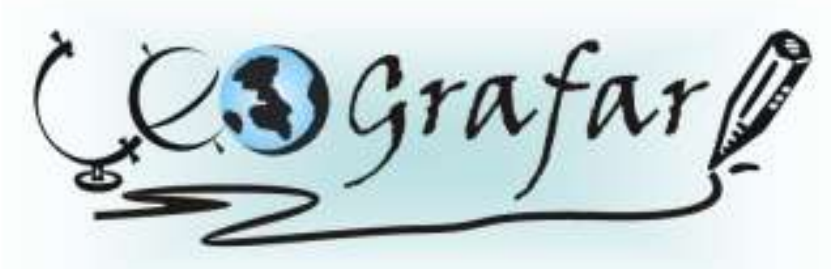

Revista Eletrônica do Programa de Pós-Graduaçāo em Geografla - UFPR

\title{
MARCOS SONOROS COMO SIGNOS IDEOLÓGICOS
}

\author{
LAWRENCE MAYER MALANSKI ${ }^{1}$
}

\begin{abstract}
RESUMO
O renascimento do interesse geográfico pela paisagem com aporte fenomenológico a partir da década de 1960 possibilitou novas abordagens sobre a paisagem, incluindo as experiências sonoras que os lugares proporcionam aos seres humanos. Assim, tal experiência é objetivada, em Geografia, pela corrente humanista-cultural. Pensar o espaço geográfico a partir de seus sons pode parecer estranho, principalmente, se aproximarmos, para tanto, os conceitos de marcos sonoros de Murray Schafer e de signos ideológicos de Mikhail Bakhtin; ambos pesquisadores de ciências díspares à Geografia. Contudo, esse artigo tem por finalidade apresentar uma possível reflexão epistemológica geográfica a respeito dessa relação, uma vez que, ambos os autores concordam que esses dois conceitos são criados a partir da interação social, adquirindo e expressando, então, significados ideológicos. Assim, marcos sonoros podem ser considerados uma forma de signos, já que representam e permitem pensar o espaço geográfico de uma comunidade, transformando-o em uma categoria social. Como exemplos de marcos sonoros, citamos as "vuvuzelas" da África do Sul e a "Mulher da Cobra" de Curitiba. Desse modo, pretendemos despertar o interesse pelo estudo dos sons dos lugares e seus significados sociais, mostrando que eles podem contribuir para uma análise diferenciada, mas, ao mesmo tempo, integrada ao complexo espaço geográfico.
\end{abstract}

Palavras-chave: Paisagem sonora; marcos sonoros; signos; contexto.

\footnotetext{
${ }^{1}$ Mestrando em Geografia pela UFPR. E-mail: law.malanski@gmail.com
} 


\title{
SOUND MARKS AS IDEOLOGICAL SIGNS
}

\begin{abstract}
The revival of geographic interest phenomenological contribution to the landscape from the 1960s, allowed new approaches to landscape, including sound experiences that places provide for human beings. So, this experience is objectified in Geography, by the theory humanitarian and cultural. Think the geographical space from their sounds could be strange, especially if approached, the concepts of sound marks of Murray Schafer and ideological signs of Mikhail Bakhtin, both researchers from the disparate sciences Geography. However, this article aims to present a possible geographical epistemological reflection about this relationship, because the authors agree that these two concepts are created from social interaction, acquiring and expressing, then ideological meanings. So, sound marks can be considered a form of signs, just because they represent thinking and allow the geographical area of a community, transforming it into a social category. Such as an example of sound marks, cite the "vuvuzelas" of South Africa and "Snake Woman" in Curitiba. Our intention is to arouse interest in the study of the sounds of the places and their social meanings, showing that they can contribute to a differentiated analysis, but at the same time, integrated the complex geographical space.
\end{abstract}

Keywords: Soundscape; sound marks; signs; context.

\section{INTRODUÇÃO - AS VUVUZELAS E A COPA 2010}

Ao acompanhar as transmissões dos jogos da Copa das Confederações 2009 ou da Copa do Mundo 2010, ambos realizados na África do Sul, certamente perceberam-se os sons das vuvuzelas (aquele tipo de corneta bastante utilizada pelos torcedores durante esses dois eventos). Tais sons marcaram os acontecimentos esportivos e motivaram discussões entre o Comitê Organizador da FIFA (órgão internacional responsável pela organização dos eventos) e os torcedores, já que o comitê ameaçou proibir o uso das cornetas nos estádios de futebol durante as partidas da Copa do Mundo devido ao intenso "barulho" provocado por elas, notados primeiramente durante a Copa das Confederações. Além de supostamente atrapalhar a comunicação das equipes durante as partidas e tirar a concentração dos atletas, estudos apontam que, devido à intensidade sonora, um torcedor deveria ficar exposto ao som emitido pela vuvuzela por no máximo quinze minutos diários sem danos à audição (SWANEPOEL et al, 2010). 
Contudo, após debates, o uso do instrumento foi liberado desde que fossem respeitados os pedidos de silêncio expostos nos telões dos estádios principalmente durante a execução dos hinos nacionais das seleções. Isso porque a corneta e seu som foram considerados pela FIFA como símbolos da África do Sul e não seria justo proibir o uso de um instrumento típico do país sede do evento esportivo (SWANEPOEL et al, 2010). Nas palavras do porta-voz do comitê organizador local da FIFA Rich Mkhondo em entrevista à Reuters Brasil "As vuvuzelas vieram para ficar e jamais serão proibidas [...] Encarem como parte de nossa cultura na África do Sul para comemorar a Copa do Mundo de 2010. Como nossos convidados, por favor, abracem nossa cultura, a maneira como comemoramos" (LOURIE, 2010).

Estima-se que a atual vuvuzela deriva de um instrumento folclórico feito de chifre de kudu (antílope que habita as regiões de savana do continente africano) utilizado para convocar reuniões de pessoas. No entanto, tais informações carecem de fontes assertivas. Além disso, nos últimos 15 anos, a nação arco-íris passou por tensões políticas e sociais envolvendo, inclusive, o fim do Apartheid e a vuvuzela e seu som se tornaram símbolos de esperança e união para muitos negros sulafricanos (SWANEPOEL et al, 2010).

Assim como tambores e pandeiros do samba podem representar o Brasil, castanholas a Espanha, a flauta-de-pã os povos andinos da Bolívia e Peru e a balalaica a Rússia, os som da vuvuzela pode representar a África do Sul. Então porque proibir um símbolo sul-africano em um evento esportivo realizado na África do Sul e que buscou valorizar a cultura local? De todo modo, se na atual sociedade ocidental o sentido visual parece receber maior importância se comparado aos demais $^{2}$, durante a Copa do Mundo 2010 foram os sons que despertaram a atenção de todos.

Ao apresentar a discussão envolvendo o uso das vuvuzelas durante os jogos da Copa do Mundo 2010 na África do Sul, chama-se atenção para os principais objetivos desse artigo: despertar o interesse pelo estudo da paisagem sonora e seus significados e propor seus sons como recurso para analisar o espaço geográfico a partir de seus signos ideológicos. Para tanto, acredita-se que os sons que formam a

\footnotetext{
${ }^{2}$ A predominância do sentido visual sobre os demais na atual sociedade ocidental, Schafer (2001) denomina "cultura do olho".
} 
paisagem sonora de um local agregam significados sociais e, assim, tornam-se símbolos, marcos culturais e geográficos.

A discussão teórica será construída a partir de revisão de literatura de duas ideias em destaque aparentemente distintas: a de paisagem sonora do ecologista sonoro Murray Schafer, e o conceito de signo do linguista Mikhail Bakhtin. Para endossar o debate, serão utilizadas, sobretudo, contribuições do filósofo Maurice Merleau-Ponty e do geógrafo Yi Fu-Tuan. Além disso, o exemplo da vuvuzela durante a Copa do Mundo 2010 permeará o artigo de modo a caracterizar a discussão.

O mapa conceitual a seguir representa as principais ideias discutidas no artigo.

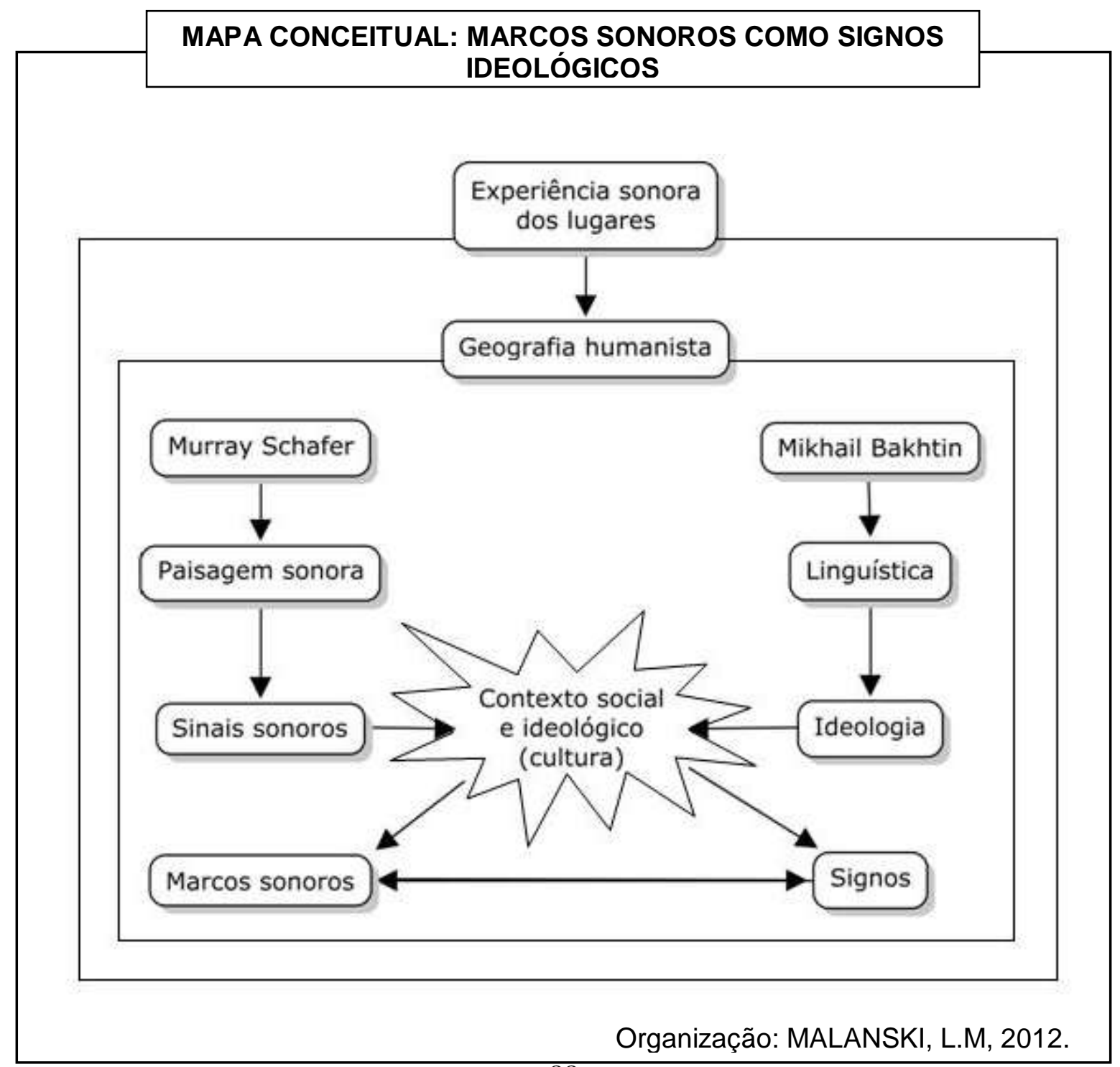




\section{OS SONS E A GEOGRAFIA}

Primeiramente, antes de iniciar-se a discussão que se pretende realizar ao longo do artigo, considera-se adequado situar o leitor quanto aos estudos dos sons pela Geografia, pois, para alguns, podem não parecer claros.

Manifestado apenas na corrente humanista da Geografia, o estudo das experiências sonoras que os lugares proporcionam aos seres humanos é recente entre os pesquisadores da área, utilizando, para tanto, muitos conceitos "importados" de campos como o paisagismo sonoro, a acústica e a produção sonora e musical. Tal estudo provém do renascimento do interesse geográfico pela paisagem na década de 1960, quando seu enfoque analítico transitou do físico e biológico e do material e econômico para o fenomenal. $\mathrm{O}$ aporte fenomenológico e trabalhos como os de Maurice Merleau-Ponty e de Yi-Fu Tuan fomentam pensar o espaço a partir de diferentes perspectivas não contempladas por outros vieses metodológicos. Com isso, os geógrafos humanistas passaram a considerar a paisagem uma construção mental essencialmente subjetiva, formada a partir da percepção e da vivência do território (MALANSKI, 2011).

Em seu livro Topofilia, Yi-Fu Tuan (1980) alerta sobre a importância dos sons para os estudos geográficos ao apontar que, apesar da sensibilidade auditiva humana não ser tão apurada quanto à de outros mamíferos, a experiência espacial é aumentada grandemente pelo sentido auditivo e que nos sentimos mais vulneráveis aos sons do que a imagem visual. Desse modo, nas palavras de Tuan "os olhos obtém informações muito mais precisas e detalhadas sobre o meio ambiente, do que os ouvidos, mas geralmente somos mais sensibilizados pelo que ouvimos do que pelo que vemos" (TUAN, 1980, p. 10).

Sendo, então, a Geografia a área do conhecimento voltada para o estudo do espaço geográfico e, além disso, a Geografia Humanista um viés teóricometodológico fundamentado na fenomenologia que propõe o estudo dos mundos percebidos, vividos, imaginados, representados individual e socialmente, por que não considerar também os sons em suas análises? Pois se sabe que eles podem revelar aspectos não contemplados pelo lance visual ou uma forma alternativa para a percepção e compreensão espacial. Merleau-Ponty (1999) destaca que o mundo é aquilo que é vivido pelo indivíduo. Assim, para que as coisas sejam percebidas é 
preciso que sejam vividas. Para tanto é necessário um corpo dotado de sentidos simultaneamente atuantes de modo a perceber os arranjos espaciais e submetê-los ao processo individual mental da representação, que dá significado ao algo percebido.

À imagem integrada do espaço construída pela mente e pelos sentidos, Tuan (1979) denomina paisagem. O interesse pela paisagem renasce na Geografia a partir da década de $1960 \mathrm{com}$ aspecto fenomenal como alternativa metodológica aos estudos algumas vezes excessivamente abstratos e teóricos realizados pelas correntes física e ecológica e a material e econômica. O aporte da fenomenologia possibilitou novas apreciações sensoriais da paisagem, como as paisagens sonoras, paisagens olfativas, paisagens táteis, paisagens biográficas (GASPAR, 2001) e, até mesmo, paisagens gustativas.

\section{OS MARCOS SONOROS DE SCHAFER}

Como principal referência para estudos dos sons dos lugares, tem-se o trabalho desenvolvido por Schafer durante o World Soundscape Project (WSP), um projeto comparativo de paisagens sonoras mundiais lançado em 1971 no Canadá. Nele Schafer (2001) caracteriza a paisagem sonora pela unidade dos sons de um determinado lugar, englobando sons de natureza agradável ou desagradável (ruído, barulho). Assim, essa terminologia contribui com a ideia de que o som de um lugar pode expressar a identidade cultural de sua comunidade. Retomando o caso da vuvuzela na Copa 2010, pode-se inferir que o som desse instrumento representa traços da cultura sul-africana.

A partir da Gestalttheorie, Schafer propõe para o estudo da percepção sonora e das paisagens sonoras a relação entre três elementos: "figura", "fundo" e "campo". Onde "a "figura" corresponde ao sinal, ou marca sonora; o "fundo" corresponde aos sons do ambiente à sua volta - que podem, com frequência, ser sons fundamentais; e o "campo", ao lugar onde todos os sons ocorrem, a paisagem sonora." (SCHAFER, 2001, p. 214). Em relação aos sons fundamentais, estes podem ser entendidos como sons que são ouvidos continuamente por determinado grupo ou sociedade de modo, muitas vezes inconsciente, formando fundos contra os quais os outros sons são percebidos. Imaginando um estádio sul-africano durante um jogo do 
campeonato, os sons emitidos pelas vuvuzelas corresponderiam à figura, os demais sons emitidos pela torcida e pelos jogadores e árbitros o fundo, enquanto o estádio se caracterizaria como o campo.

Conforme Merleau-Ponty (1999) a figura sobre o fundo é o dado sensível mais simples, sem o qual um fenômeno não pode ser percebido. “O 'algo' perceptivo está sempre no meio de outra coisa, ele sempre faz parte de um 'campo'. Uma superfície verdadeiramente homogênea, não oferecendo nada para se perceber, não pode ser dada a nenhuma percepção." (MERLEAU-PONTY, 1999, p. 24). Se nessa frase de Merleau-Ponty "superfície" fosse substituída por "campo" a relação também seria valida.

Nota-se, então, que a paisagem sonora é formada pela união e sobreposição dos sons de um lugar. Para tanto, Schafer (2001) utiliza os termos hi-fi (alta fidelidade) e low-fi (baixa fidelidade), provenientes dos estudos da acústica para distinguir duas formas de união e sobreposição desses eventos acústicos. A paisagem sonora hi-fi é aquela em que os sons separados podem ser claramente ouvidos, portanto, há perspectiva - figura e fundo. Enquanto numa paisagem sonora low-fi os sinais acústicos são encobertos pelo alto nível de ruído ambiental. Os sons de um estádio durante um jogo da Copa do Mundo 2010 poderiam ser caracterizado como uma paisagem sonora low-fi, pois apresentaria alto nível de "barulho" com destaque para os sons de várias vuzuzelas ecoando ao mesmo tempo.

Os sons de primeiro plano - figura - de uma paisagem sonora são denominados por Schafer como sinais sonoros. Se esses sinais são reconhecidos por uma comunidade e seus visitantes, passam a ser designados como marcos sonoros geográficos, uma analogia aos marcos geográficos - landmarks (SCHAFER, 2001). Em relação a estes marcos, Paul Claval (2001) aponta que o espaço onde se desenvolve a vida social é apropriado por grupos que organizam formas de marcar sua passagem e afirmar a posse do mesmo, fazendo uso para tanto de marcos geográficos (construções, monumentos, rituais entre outros). Assim, tais grupos delimitam o espaço pela multiplicação de marcas que lembram à identidade, à ideologia, comum.

Pode-se entender que, do mesmo modo que os marcos geográficos caracterizam e identificam um lugar e a cultura de sua população, os marcos sonoros podem ter a mesma função, tornando-se "marcos sonoros geográficos" 
(SCHAFER, 2001). Além disso, ambos são construídos e reconhecidos socialmente. Convém lembrar-se do exemplo histórico das vuvuzelas. Ao serem utilizadas para convocar reuniões tribais, os sons das cornetas abrangiam e delimitavam espaços, assim como os marcos geográficos. Todas as pessoas dentro desses espaços estariam sob influência de determinada organização social que utilizava a corneta como forma de comunicação. Desse modo, um som de primeiro plano como o ecoar de uma vuvuzela só passa a ser considerado um marco sonoro quando recebe uma carga de valores socialmente formulados, tornando-se, então, um signo.

\section{OS SIGNOS IDEOLÓGICOS DE BAKHTIN}

O ser humano vive imerso em espaços repletos de signos e os cria para representar fenômenos naturais e sociais, para a compreensão de acontecimentos ditos sobrenaturais e, principalmente, para perpetuar sua consciência. Tais signos podem ser imagens, sons, músicas, palavras, gestos, objetos, rituais, elementos naturais entre outros. Contudo, tal ambiente não é um amontoado de objetos, mas um intricado sistema de relações sociais onde estão inseridos valores, vivências e atitudes.

Para Bakhtin, a natureza do signo é social, ideológica e dialógica, sendo o resultado de um consenso entre indivíduos em um processo de interação. Entendese dialogismo, conforme Kozel (2009), como sendo as relações sociais estabelecidas entre os sujeitos que refletem, incorporam, entrelaçam e perpassam os discursos estabelecidos. Com isso, os sujeitos se tornam históricos e sociais, uma vez que reúnem diferentes discursos de outros e formam redes complexas, que completam e polemizam esses discursos entre si. Assim sendo, "Não basta colocar face a face dois Homo sapiens quaisquer para que os signos se constituam. É fundamental que esses indivíduos estejam socialmente organizados, que formem um grupo (uma unidade social): só assim um sistema de signos pode constituir-se." (BAKHTIN, 2002, p. 33). Como exemplo disso, retoma-se a questão dos sons das vuvuzelas como signos socialmente construídos e utilizados para a representação de fenômenos sociais.

Infere-se que mudanças na organização social e nas condições de interação e comunicação produzem mudanças no signo. Portanto, o signo materializa a 
comunicação historicamente constituída entre indivíduos no meio social (SEVERO, 2008). As mudanças ocorridas na sociedade africana transformaram o som da vuvuzela, um signo originalmente tribal, em sinônimo de união e esperança para os negros durante o período do Apartheid. Em seguida, tornou-se marco sonoro da Copa do Mundo 2010, adaptando-se à realidade social vivida em determinada época. Com relação a essa questão, Bakhtin (2002, p. 33) ressalta que:

\begin{abstract}
Cada signo ideológico é não apenas um reflexo, uma sombra da realidade, mas também um fragmento material dessa realidade. Todo fenômeno que funciona como signo ideológico tem uma encarnação material, seja como som, como massa física, como cor, como movimento do corpo ou como outra coisa qualquer.
\end{abstract}

A soma dos comportamentos, dos objetos, dos saberes, das técnicas, dos conhecimentos e dos valores acumulados por grupos socialmente organizados, do qual as pessoas fazem parte, denomina-se cultura (CLAVAL, 2001). Apesar de compreendida como um conjunto de técnicas e de comportamentos individuais e coletivos, Claval (2001), afirma que a cultura é um conjunto não fechado e imutável, pois o contato com diferentes culturas (choque cultural), as inovações e iniciativas oriundas de dentro do próprio grupo constituem fontes de enriquecimento e transformação cultural.

Para Merleau-Ponty (1999) o mundo cultural, composto por objetos e comportamentos, é conformado pelo movimento intencional da subjetividade, que impregna de significados antropológicos o mundo natural. Para a pessoa, todo objeto é primeiramente natural e constituído de cores, odores, sabores, qualidades sonoras e táteis para que possa, então, fazer parte de sua vida. Num segundo momento, esse objeto traz implícito a marca da ação humana na sua constituição de acordo com a experiência pessoal.

De modo semelhante, para Tuan (1998), a cultura não é só conduzida pela imaginação como é um produto dela. Assim sendo, cultura pode ser compreendida como a totalidade dos significados por meio da qual a pessoa escapa do seu estado animal de ser (TUAN, 1998). A partir dessa perspectiva, assume-se que a dimensão biológica, responsável pelas percepções, fornece subsídios para que a dimensão cultural mostre e potencialize a dimensão subjetiva humana. 
Por ideologia entende-se todo o conjunto de reflexos e interpretações da realidade natural e social que povoa o cérebro humano e se expressa por meio de signos (SEVERO, 2008). "Tudo que é ideológico possui um significado e remete a algo situado fora de si mesmo" (BAKHTIN, 2002, p. 31). Assim, os signos personificam a ideologia. Se um elemento sígnico não contiver conteúdo ideológico provindo do contexto a que pertença, não poderá ser considerado um signo perfeito. Portanto, este deve ser contextualizado para ganhar significação. Além disso, assim como o signo é a materialização da ideologia social, ele só pode ser tido como tal quando compreendido e dotado de valor por pessoas de um grupo socialmente organizado. Desse modo, os significados dos diferentes signos são construídos socialmente a partir do dialogismo (diálogo), entendido como a relação entre pessoas na qual são incorporados diferentes valores e discursos através da recepção/compreensão de enunciados. A enunciação é, sob diferentes formas de linguagens, a realização exterior da atividade mental encaminhada por uma orientação social (KOZEL, 2007).

Merleau-Ponty (1999) preocupa-se com a relação signo e significado através, principalmente, da linguagem. Para ele, a existência de um contexto inexpresso é um conceito que daria à sentença caráter vivo e não simplesmente mecanicista. $A$ linguagem, na medida em que consiste de signos enunciativos, dá corpo ao pensamento fazendo a mediação com os objetos e com outrem. Ela é o sistema de representações e relações simbólicas que os seres humanos produzem como síntese da pluralidade de suas experiências.

\section{OS MARCOS SONOROS COMO SIGNOS IDEOLÓGICOS}

Os diferentes apontamentos referentes às vuvuzelas feitas até então permitem afirmar que tanto o instrumento quanto seu som fazem parte da cultura sul-africana e, portanto, estão inseridos em diferentes relações sociais ao longo do tempo. A partir desses apontamentos, exemplifica-se a relação entre marcos sonoros e signos ideológicos. Assim, sons podem ser considerados marcos sonoros a partir da interação social (dialogismo) e adquirem então significado ideológico. Além disso, tal processo envolve aspectos individuais, como a aculturação, o estado mental e a relação da pessoa com o espaço e sociedade. O código ideológico de 
comunicação é o signo e os marcos sonoros podem ser considerados como tal, pois carregam denotações referenciais ideológicas. Sintetiza-se isso no diagrama a seguir:

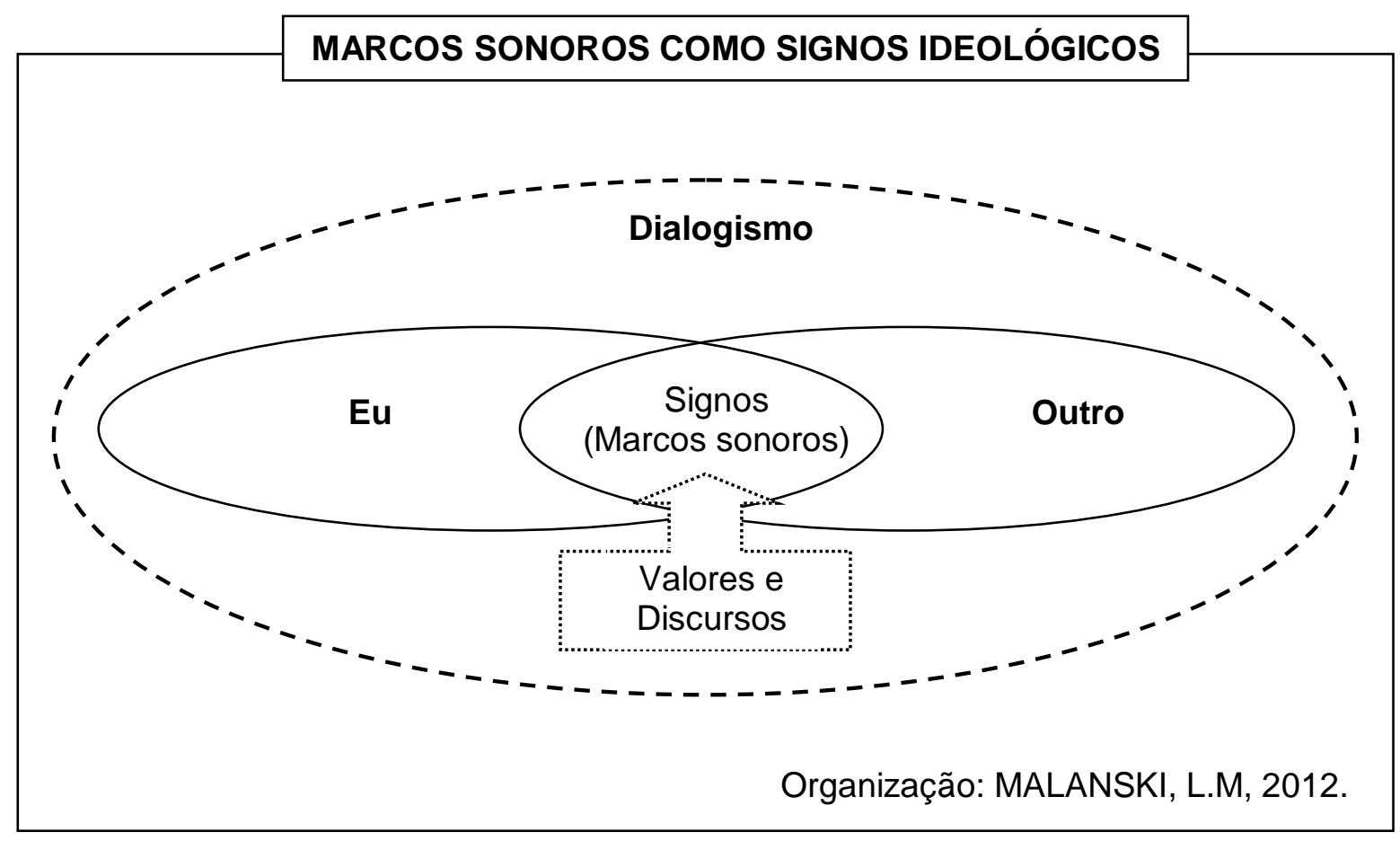

Pesquisas anteriores apontam que ruídos ${ }^{3}$ universais ao serem percebidos por pessoas de uma determinada comunidade podem adquirir significado ideológico. É o caso de resultados divulgados no trabalho "Geografia Escolar e Paisagem Sonora", onde sons cujas fontes eram tratores e caminhões foram representados graficamente em mapas mentais como emitidos por um trem (MALANSKI, 2011). Isso se explica pelo fato de que as pessoas que os representaram pertencerem a uma comunidade onde o trem está presente de modo marcante no cotidiano do lugar (no caso o bairro Barreirinha, em Curitiba) enquanto tratores e caminhões não estão. Assim, a competência de ser flexível e de obter diversos significados são próprias do signo porque ele é pensado sempre em relação com a sociedade. Quando o som não é orientado para um contexto social, quando ele é apenas identificado, torna-se somente um sinal.

Atualmente, pode parecer difícil pensar em sons que não sejam universais. Com a Revolução Industrial surgiram novos fenômenos acústicos que rapidamente

\footnotetext{
${ }^{3}$ Entende-se ruído como sendo som de natureza desagradável.
} 
se espalharam pelo mundo. Ouve uma globalização de sons como, por exemplo, dos motores a combustão dos automóveis, aviões, helicópteros e trens, das buzinas, do burburinho de pessoas concentradas em grandes centros urbanos e dos aparelhos eletroacústicos, portáteis ou não. Mas em relação ao exemplo das vuvuzelas durante a Copa do Mundo, nota-se que sons locais desconhecidos por outras comunidades (sons não universais) podem despertar emoções e sentimentos a ponto de, até mesmo, serem considerados irritantes. O som das vuvuzelas é um signo típico da sociedade sul-africana, mas pode soar como um ruído perturbador para outras, distantes do contexto local.

Retomando as ideias de Schafer, pode-se considerar o som das vuvuzelas durante a Copa do Mundo 2010 como um evento sonoro, já que despertou a emoção e sentimentos de todos os envolvidos com o acontecimento esportivo. Além disso, o som das vuvuzelas tornou-se um marco sonoro geográfico da Copa 2010 e, também, da África do Sul para muitas sociedades afastadas do contexto local. Certamente, muitos ao lembrarem do evento esportivo e de seu país sede lembrarão também de seu som característico. Assim, o que soava apenas como um ruído para alguns, tornou-se um signo, um marco sonoro geográfico. Seguramente, o significado do som das vuvuzelas não é o mesmo para os sul-africanos e para as demais sociedades, já que para os primeiros ele está diretamente relacionado à cultura e tradição local, enquanto os segundos o conheceram recentemente e o relacionarão com o evento esportivo de 2010 ou com o país África do Sul de um modo geral. Contudo, em ambos os casos ele é um exemplo do que se pretende relacionar aqui. Além disso, convém associar a ele a ideia de dialogismo de Bakhtin, uma vez que pessoas distintas, com vivências distintas, incorporaram e/ou polemizaram discursos de outras.

Além dos sons universais frutos da Revolução Industrial e de sons criados por sociedades locais como o da própria vuvuzela, em seu livro "A Afinação do Mundo" Schafer cita um exemplo de som natural considerado por ele como um marco sonoro:

O mais impressionante marco sonoro geográfico que já escutei ocorreu na Nova Zelândia. Em Tikitere, Rotorua, grandes campos de enxofre fervente, espalhados ao longo de muitos acres de terra, são acompanhados por estranhos ribombos e gorgolejos subterrâneos. $\mathrm{O}$ lugar é uma chaga pustulenta na pele da terra, com infernais efeitos sonoros em ebulição espalhando-se com os ventos (SCHAFER, 2001, p. 48). 
Nota-se no trecho acima que Schafer faz analogias relacionadas ao seu contexto cultural para caracterizar o marco sonoro em questão. A última frase, em especial, possui forte caráter ideológico. Certamente, pessoas provindas de contextos sócio-culturais diferentes apresentariam descrições distintas para o acontecimento sonoro em questão. Assim, nota-se que os sons ditos "naturais" também podem se tornar signos, pois apesar deles não serem produzidos pelos seres humanos e seus instrumentos, também podem receber e agregar valores sociais.

Como demais manifestações espaciais, a paisagem sonora também é passível de mapeamento. Podem-se utilizar técnicas da cartografia colaborativa para, por exemplo, mapear as fontes emissoras de sons em uma cidade para o monitoramento da qualidade ambiental, ou seus marcos sonoros como sons característicos de determinada comunidade. Toda cidade possui marcos sonoros capazes de serem cartografados. Na rede mundial de computadores é possível encontrar projetos de mapeamentos sonoros como o NYSoundmap (de Nova lorque, EUA), o Montréal Sound Map (de Montreal, Canadá), o SeoulSoundMap (Seul, Coréia do Sul) e o Map of Sounds of Lisboa (de Lisboa, Portugal), que disponibilizam ao usuário desde os locais mais "barulhentos" do centro urbano até seus marcos sonoros específicos.

Além disso, podem-se desenvolver trabalhos com a cartografia mental a partir da percepção e representação da paisagem sonora, pois assim como os elementos visuais do espaço, os sons são também dados à mente humana. No entanto, diferentemente da visão, a audição favorece melhor a imaginação humana ao oferecer estímulos que remetam à vivência e as experiências pessoais (MALANSKI, 2011).

\footnotetext{
${ }^{4}$ A discussão sobre sons ditos naturais ou humanos é a mesma que se tem sobre paisagens naturais e paisagens culturais: o ser humano, sua técnica e seus sons não fariam parte da natureza?
} 


\section{APONTAMENTOS FINAIS}

A experiência sonora que os lugares proporcionam aos seres humanos é objetivada, em Geografia, pela corrente humanista. A Geografia, como todo, almeja o estudo do espaço geográfico, repleto de representações e significados individuais e sociais que caracterizam a singularidade e, ao mesmo tempo, a pluralidade dos lugares. Tal singularidade pode ser percebida através dos sentidos humanos, principalmente pela visão. Contudo, a audição também pode contribuir para a experiência espacial fornecendo elementos não contemplados pelos demais sentidos. Assim, pode-se estudar o espaço geográfico a partir do conjunto de sons dos lugares - chamados de paisagem sonora.

A paisagem sonora de um lugar é composta por sons de fundo e sons de figura, estes chamados de sinal sonoro. Quando determinado sinal é reconhecido pela sociedade local e seus visitantes, torna-se um marco sonoro. Como este marco tem existência social, pode-se dizer então que ele é uma forma de signo, que materializa e expressa à ideologia local. Além disso, pode ser mapeado assim como demais informações espaciais.

O espaço geográfico reflete e materializa a cultural das diferentes sociedades humanas através da organização espacial e de suas técnicas. Tais sociedades encerram-no em sistemas de representações que permite pensá-lo através, principalmente, das diferentes formas de signos. Portanto, o espaço é transformado em objeto de discurso e torna-se uma categoria social (Claval, 2001). Desse modo, aproximam-se conceitos aparentemente distintos: os marcos sonoros de Schafer e os signos de Bakhtin, já que ambos afirmam a importância da interação social e do contexto local como origem dos marcos sonoros e signos, o que pôde ser notado com o exemplo da vuvuzela na África do Sul, um instrumento que emite um som compreendido historicamente pela sociedade sul-africana e que passou a ser considerado marco sonoro do país com a Copa do mundo 2010.

Com isso, pretende-se despertar o interesse pelo estudo dos sons dos lugares e seus significados sociais, mostrando que eles podem contribuir para uma análise diferenciada, mas, ao mesmo tempo, integrada ao complexo espaço geográfico a fim de compreendê-lo e torná-lo cada vez melhor em diferentes aspectos. 


\section{REFERÊNCIAS}

BAKHTIN, Mikhail (VOLOCHÍNOV, Valentin.). Marxismo e Filosofia da Linguagem. São Paulo: Hucitec, 2004.

CLAVAL, Paul. A Geografia Cultural. Florianópolis: Ed. da UFSC, 2001.

GASPAR, Jorge. 0 retorno da paisagem à geografia: apontamentos místicos. Finisterra: Revista portuguesa de geografia, Lisboa: n. 72, 2001. p. 83-99. ISSN 0430-5027

Disponível em: http://www.ceg.ul.pt/finisterra/numeros/2001-72/72_08.pdf Acesso em: 28 jun. 2011.

KOZEL, Salete Teixeira. As linguagens do cotidiano como representações do espaço: uma proposta metodológica possível. In: 12 EGAL - Encuentro de geógrafos de América Latina, 2009, Montevideo. Anais do 12 EGAL. Montevideo: Editora Universidad de la República, 2009.

Disponível em: http://egal2009.easyplanners.info/area02/2088_KOZEL_Salete.pdf Acesso em: 16 ago. 2011.

LOURIE, Gugulakhe. Vuvuzelas não serão proibidas, diz comitê da Copa. Reuters Brasil. 14. Jun. 2010. Artigos.

Disponível em: http://br.reuters.com/article/idBRSPE65D09B20100614

Acesso em: 13. abr. 2012.

MALANSKI, Lawrence Mayer. Geografia Escolar e Paisagem Sonora. RA'E GA: o espaço geográfico em análise. Curitiba: UFPR, Departamento de Geografia, n. 22, 2011. p. 252-273. ISSN 2177-2738.

Disponível em: http://ojs.c3sl.ufpr.br/ojs2/index.php/raega/article/viewArticle/21775 Acesso em: 15 ago. 2011

MERLEAU-PONTY, Maurice. Fenomenologia da Percepção. São Paulo: Martins Fontes, 1999.

SCHAFER, Raymond Murray. A afinação do mundo: uma exploração pioneira pela história passada e pelo atual estado do mais negligenciado aspecto do nosso ambiente: a paisagem sonora. São Paulo: Ed. da UNESP, 2001.

SEVERO, Cristine Gorski. Sobre o sujeito na perspectiva (do Círculo) de Bakhtin. Revista Eletrônica do Instituto de Humanidades, Grande Dourados, MS, v. VII. n, XXV, p. 45-60, abr-jun 2008. ISSN 1678-3182

Disponível em: http://publicacoes.unigranrio.edu.br/index.php/reihm/article/view/9 Acesso em: 10 jul. 2011. 
SWANEPOEL, De Wet; HALL, James W; KOEKEMOER, Dirk. Vuvuzela - good for your team, bad for your ears. SAMJ: South African Medical Journal, vol.100 n.2 Cape Town Fev. 2010.

Disponível em: http://www.scielo.org.za/scielo.php?pid=S025695742010000200015\&script=sci_arttext

Acesso em: 31 ago. 2012.

TUAN, Yi-Fu. Topofilia: um estudo da percepção, atitudes e valores do meio ambiente. São Paulo: Ed. Difel, 1980.

TUAN, Yi-Fu. Escapism. Baltimore: The Johns Hopkins University Press, 1998.

(Recebido em: 18/04/2012. Aceito em 25/09/2012). 